\title{
Crosstalk between T Helper Cell Subsets and Their Roles in Immunopathogenesis and Outcome of Polytrauma Patients
}

\author{
Surbhi Khurana ${ }^{1}$, Nidhi Bhardwaj ${ }^{2}$, Subodh Kumar $^{3}$, Sushma Sagar ${ }^{4}$, Rahul Pal ${ }^{5}$, Kapil Dev Soni ${ }^{6}$, Richa Aggarwal , \\ Rajesh Malhotra ${ }^{8}$, Purva Mathur ${ }^{9}$
}

\begin{abstract}
Purpose: One of the leading causes of morbidity and early-age mortality across the globe is trauma. It disrupts immune system homeostasis and intensely affects the innate and adaptive immune responses, predisposing patients to posttrauma complications and poor outcomes. Most of the studies on posttrauma cellular immune response have been centered on the Thelper-1-T helper-2 imbalances after trauma. This study was conducted to understand the role of circulating novel T helper cells in the acute posttraumatic period and clinical outcome of trauma patients. Materials and methods: Signature cytokines and transcription factors of circulating Th (T helper)-9, Th-17, Th-22, and regulatory T helper cells were studied using flowcytometry along with serum biomarkers in 49 patients with polytraumatic injuries admitted to a tertiary care hospital. The patients were followed up until their outcome. The results were correlated with their clinical outcomes.

Results: In patients who died, higher nTreg, iTreg, Tr1 (early-phase), and higher IRF4+Th-9, IL17+ Th-17, and RORYT+ Th-17 (mid-phase) were seen. However, by the late phase, only RORYT+ Th-17 remained higher. Serum IL- 6 and PCT were found to be consistently higher. In survivors, higher Th-3 (early phase), Th-22 (mid-phase), and IRF4+Th-9, IL17+ Th-17, nTreg, Th-3 (late phase) were observed to have played a protective role. Serum IL-2, IL-4, IL-17A and IL-22 were significantly higher in survivors.

Conclusion: Different T helper subsets were observed to be playing pathogenic and protective roles in different phases of trauma and could be used for early prognostication and make way for noninvasive management of critically injured trauma patients by immunomodulation.

Keywords: iTregs, nTregs, Th-17, Th-22, Th-3, Th-9, Tr1, Trauma.

Indian Journal of Critical Care Medicine (2020): 10.5005/jp-journals-10071-23577
\end{abstract}

\section{INTRODUCTION}

Trauma is one of the leading global causes of early-age mortality. ${ }^{1-3}$ Despite the revolutionary innovations and advancements in the healthcare sector and increased enforcement of strategies and laws to reduce road traffic injuries, the burden of injuries continues to be high and trauma remains a significant cause of morbidity and mortality in the developed and developing world. ${ }^{4,5}$

Worldwide, since 1990, there has been a noteworthy declining trend in the rates of disability-adjusted life years (DALYs) of all the major causes of injury; however, the patterns vary widely by region, cause, sex, age, and time. Nonetheless, the burden of life-threatening injuries remains high in some parts of the world including India, particularly afflicting the socioeconomically productive population-young adults. ${ }^{5,6}$

A traumatic injury disrupts immune system homeostasis, profoundly affecting the innate and adaptive immune responses, and renders patients highly vulnerable to opportunistic infections and predisposing them to posttrauma complications. ${ }^{7-9}$

The disruption of the immune system constitutes an instantaneous beginning of activation of the innate immune response, which translates into a rapid cellular immune response that aims to end the dangerous situation for the recipient of the traumatic insult but can also result in severe complications and death. ${ }^{10-13}$

The adaptive immune cells include lymphocytes-broadly subdivided into three major populations based on functional and phenotypic differences: $B$ lymphocytes (B cells), T lymphocytes ( $T$ cells), and innate lymphoid cells (ILCS), which include the well-understood natural killer (NK) cells. B and T lymphocytes generate the adaptive immune response- - distinguished

\begin{abstract}
1,2,9 Department of Laboratory Medicine, JPNA Trauma Center, All India Institute of Medical Sciences, New Delhi, India

${ }^{3,4}$ Department of Trauma Surgery and Critical Care, JPNA Trauma Center, All India Institute of Medical Sciences, New Delhi, India

${ }^{5}$ Immunoendocrinology Lab, National Institute of Immunology, New Delhi, India

6,7Department of Anesthesia and Critical Care, JPNA Trauma Center, All India Institute of Medical Sciences, New Delhi, India

${ }^{8}$ Department of Orthopedics, JPNA Trauma Center, All India Institute of
\end{abstract} Medical Sciences, New Delhi, India

Corresponding Author: Purva Mathur, Department of Laboratory Medicine, JPNA Trauma Center, All India Institute of Medical Sciences, New Delhi, India, Phone: +919810350650, e-mail: purvamathur@ yahoo.co.in

How to cite this article: Khurana S, Bhardwaj N, Kumar S, Sagar S, Pal R, Soni KD, et al. Crosstalk between T Helper Cell Subsets and Their Roles in Immunopathogenesis and Outcome of Polytrauma Patients. Indian J Crit Care Med 2020;24(11):1037-1044.

Source of support: All India Institute of Medical Sciences, New Delhi Conflict of interest: None

antigen-specific immune response that also gives rise to immune memory. Innate lymphoid cells have features of both innate and adaptive cells. ${ }^{14-16}$

T lymphocytes include two major cell types-T helper (Th) cells and T cytotoxic (Tc) cells-that can be differentiated from one another by the presence of membrane glycoproteins on their surfaces-either CD4 or CD8, respectively. ${ }^{14}$ 
Ideally, a balanced immune (pro- and anti-inflammatory) response leads to a swift clearance of debris and initiates effective tissue repair and regeneration; however, sometimes, adverse immunological events can be caused by individual factors of the patient or aggravated tissue damage after hemorrhage, nosocomial infection, or extended surgical intervention. ${ }^{17}$

Most of the studies on cellular immune response following trauma have been centered on the Th-1-Th-2 imbalances after trauma. Moreover, most of the studies have been done using serum or plasma. Since the discovery of the Th-1/Th-2 dichotomy, it has been seen that cytokines produced by the Thelper (Th) cells play a critical role in immune cell differentiation, effector subset commitment, and directing the effector response.

Cytokines such as interferon (IFN), interleukin (IL), and growth factors (GFs) are often categorized into pro-inflammatory and anti-inflammatory and linked to Th-subsets expressing them. ${ }^{18}$ The development of new technologies, including multicolor flowcytometry and the engineering of fate-mapping and cytokine reporter mice, has led to the discovery and definition of novel subsets of T-helper cells, namely Th-9, Th-17, Th-22, and Treg cells, in the past few years. These cells are characterized by their specific cytokine profiles. The roles of these newly described subsets, especially in the context of traumatic injuries, have not been fully elucidated.

Th- 9 cells producing IL-9 have been seen to participate in the pathogenesis of many diseases, such as allergic inflammation, tumor, and parasitosis, and might be involved in pathogen immunity and immune-mediated diseases. ${ }^{19-21}$

Th-17 cells appear to play a critical role in sustaining the inflammatory response and their presence is closely associated with autoimmune diseases, which makes them an attractive therapeutic target. $^{22-24}$

Th-22 cells predominantly produce IL-22 and do not produce IL-17 or IFN- $\gamma \cdot{ }^{25-28}$ Th-22 cells have shown both pro- and antiinflammatory activities in the limited number of studies done on this subset. ${ }^{29-31}$

Thus far, no study has been done on their role in traumaimmunopathogenesis. Tissue regeneration is a fundamental process after trauma. Thus, these new effector T-cells may be playing a major role in the posttrauma immune response.

There is now great interest in immunosuppressive approaches and in the possible use of regulatory Thelper (Treg) cells for treating immune-mediated inflammatory diseases. ${ }^{32,33}$ An unexpected recent finding has shown that Treg lymphocytes do not suppress, and may even enhance IL-17 production by T-cells. ${ }^{34,35}$ Thus, we conducted a prospective cohort study to correlate the peripheral blood lymphocytic activities during the acute posttraumatic period and the clinical outcomes of the patients, on a single-cell level via flowcytometry.

\section{Materials and Methods}

This study was conducted at the JPNA Trauma Centre of the All India Institute of Medical Sciences, New Delhi. A total of 49 polytrauma patients who were directly admitted within 24 hours of injury to the emergency department were included in the study. The study was approved by the institutional ethical committee. Patients with malignancies, history of steroid use, or other known immunodeficiency state, chemical or burn injuries, on hormone therapy, chronic disease of the liver, kidney, or lung, isolated traumatic brain injury, coagulation disorders, pregnant/lactating women, and post-splenectomy patients were excluded.
Five milliliters of whole blood on the day of admission (considered as day 0) was collected before any treatment was administered. Thereafter, on days 2, 5, 10, and day of discharge (whenever applicable), samples were collected as follow-ups. Blood was divided equally in heparinized (BD vacutainer sodium heparin 75 USP units, BD Frankline Lakes NJ, USA) and plain vials. Serum was separated from the plain vial and stored at $-80^{\circ} \mathrm{C}$ for serum cytokines and biomarker analyzes. The heparinized blood was processed immediately for intracellular cytokine assay to prevent cell death over time. Whole blood samples were divided equally into two tubes and supplemented with $10 \%$ fetal bovine serum (FBS). One was stimulated with $10 \mathrm{ng} / \mathrm{mL}$ of Phorbol 12-myristate 13-acetate (PMA) (No. P 8139, Sigma-Aldrich, St. Louis, MO, USA), with $10 \mu \mathrm{g} / \mathrm{mL}$ of ionomycin calcium salt from Streptomyces conglobates, (catalog number 10634, Sigma-Aldrich, St. Louis, MO, USA), incubated at $37^{\circ} \mathrm{C}$ in $5 \%$ carbon dioxide $\left(\mathrm{CO}_{2}\right)$ with $1 \mathrm{mg} / \mathrm{mL}$ of brefeldin-A solution (BD GolgiPlug Protein Transport Inhibitor, BD, San Jose, CA, USA) to inhibit protein secretion for 4 hours. In parallel, the other tube, taken as the basal (unstimulated) tube was also treated similarly, but without stimulation to serve as a baseline for comparison.

Table 1 details the markers used to study the Thelper subsets. Whole peripheral blood stimulated for 4 hours was then stained with anti-CD4 tagged with APC-Cy7, the anti-signature cytokine antibodies, and anti-transcription factor antibodies specific for each subset studied. For all the subsets, CD3+ lymphocytes were first gated, followed by gating of CD4+ Thelper lymphocytes, and further each lymphocytic subset was identified and assessed in unstimulated and stimulated blood. The percentage of each Th-cell subset depicts the percentage of that subset of the total CD+T cells.

The LEGENDplex Human Th Cytokine Panel (13-plex) (Biolegend, San Diego, CA, USA) was used to assess the levels of IL-5, IL-13, IL-2, IL-6, IL-9, IL-10, IFN- $\gamma$, TNF- $a$, IL-17A, IL-17F, IL-4, IL-21, and IL-22 in the sera of patients and controls, as per the manufacturer's instructions. The procalcitonin (PCT) was performed using the automated enzyme-linked fluorescent assay (ELFA)-based immunoassay method (Minividas, Biomeriux Ltd.).

For the present study, a nine-color experiment was used, and nine different single controls of the same origin were used to compensate spill-over between the fluorochrome. The results were acquired on the FACS ARIA III flow cytometer equipped with blue, red, and violet lasers. Spectral overlap values were automatically calculated by the software, BD FACS Diva, and applied to the experiment. Isotypes were used to check the specificity of the antibodies. FCS Express 6 was used for data analysis.

\section{Statistical Methods}

Data were calculated and presented graphically as the mean \pm standard error of the mean (SEM). A difference in the experimental

Table 1: T helper subsets assessed in the study

\begin{tabular}{lll}
\hline Cell subsets & Functionally active & $\begin{array}{l}\text { Transcriptionally } \\
\text { active }\end{array}$ \\
\hline Thelper-1 & CD4+IFN- - +Th-1 & \\
Thelper-2 & CD4+IL-4+Th-2 & \\
Thelper-9 & CD4+IL9+Th-9 & CD4+IRF4+Th-9 \\
Thelper-17 & CD4+IL-17A+Th-17 & CD4+RORYT+Th-17 \\
Thelper-22 & CD4+IL-22+Th-22 & CD4+AhR+Th-22 \\
Regulatory Thelper & CD4 ${ }^{+}-\mathrm{IL}-10^{+}$Tr1 & CD4 ${ }^{+}$CD25 $5^{+}$FOXP3 $^{+}$ \\
& & nTreg \\
& CD4 ${ }^{+}$TGF- $\beta^{+}$Th-3 & CD4 ${ }^{+}$FOXP3 $^{+}$iTreg \\
\hline
\end{tabular}


means was considered significant if a $p$ value $\leq 0.05$ was obtained. Results were analyzed by the Mann-Whitney test for multiple comparisons. Differences were considered significant with $p$ values $\leq 0.05$. Mean \pm SEM of the patients were compared with those of the controls with the help of a nonparametric $t$-test.

Complete clinical details of the patients were recorded until their discharge/death to correlate the clinical outcome of the patients with their levels of T helper cells and biomarkers.

\section{Results}

The T helper cells' responses were compared in survivors ( $n=$ 42 ) and nonsurvivors $(n=7)$ polytrauma patients. The mean hospital stay among nonsurvivors was $22.42 \pm 25.56$ days after injury (median: 8 days; range: 1-65 days). Day 10 samples could be obtained from only three out of seven nonsurvivors cases. The predominant injuries among these polytrauma patients were trauma to the chest [26 (53\%)], followed by abdominal [17 (35\%)] and orthopedic [6 (12\%)], respectively.

The mean age of survivors and nonsurvivors was $29.5 \pm 9.2$ and $40.4 \pm 12.4$ years, respectively. The study population predominantly comprised of males' [43 (88\%) patients]. The injury severity scores ranged from 5 to 38 (survivors) and 24 to 36 (nonsurvivors). The mean hospital stay was $7.5 \pm 12.4$ (survivors) and $22.4 \pm 27.6$ (nonsurvivors) days. Total $18(43 \%)$ and 5 (71\%) survivors and nonsurvivors, respectively, underwent surgeries. Posttrauma complications, ventilator-associated pneumonia (VAP), sepsis/ systemic inflammatory response syndrome (SIRS), and multi-organ dysfunction syndrome (MODS)/acute respiratory distress syndrome (ARDS), developed in seven (14.3\%) patients. The demographic details of the fatal cases $(n=7)$ are given in Table 2 .

\section{Dynamics of T Helper Subsets Based on Clinical Outcome of Polytrauma Patients}

Figure 1 shows the comparison of T helper subsets in survivors and nonsurvivors. The Th-1 response was higher in survivors than in nonsurvivors on days 0,2 , and 10 and this elevation was found to be statistically significant on day $10(p=0.0121)$. However, it was found to be depressed in survivors on day 5 ( $p=0.0263$ ) (Fig. 1A). In nonsurvivors, a higher Th-2 response was observed on day 0 ( $p=$ $0.00145)$. The Th-2 response was also found to be higher in survivors from day $2(p=0.0087)$ till day $10(p=0.0364)$, and it was much higher than the Th-1 response (Fig. 1B). A higher IL-9-producing Th-9 cells were observed on day $0(p=0.0015)$ in nonsurvivors, and day 2 onward they were higher in survivors, but this difference was not statistically significant (Fig. 1C). From day 0 until day 5 ( $p=0.0147$ ) CD4+IRF4+Th-9 cells were higher in nonsurvivors, and contrastingly, on day 10, they were higher in survivors ( $p=$ 0.0303) (Fig. 1D). IL17+ Th-17 cells were higher in survivors till day $10(p=0.0091)$, except on day 5 , when a peak of IL17A+ cells was observed in nonsurvivors ( $p=0.019$ ) (Fig. 1E). CD4+RORYT+Th-17 cells were higher in nonsurvivors on all days of follow-up except for day 0 but were statistically significantly higher in nonsurvivors on day $5(p=0.0147)$ and day $10(p=0.0364)$ (Fig. 1F). IL-22+Th-22 cells were higher in survivors on all the days of follow-up except day 0 and were found to statistically significantly high on day 5 ( $p$ $=0.0303$ ) (Fig. 1G). The AhR-producing T helper cells were higher in survivors, like the IL-22-producing cells, and this elevation was statistically significant on day $2(p=0.003)$ (Fig. 1H). nTregs were higher in nonsurvivors from day $0(p<0.0001)$ until day 5 ( $p=$ $0.0147)$, but lower on day 10 ( $p=0.0256)$ (Fig. 1l). iTreg cells were

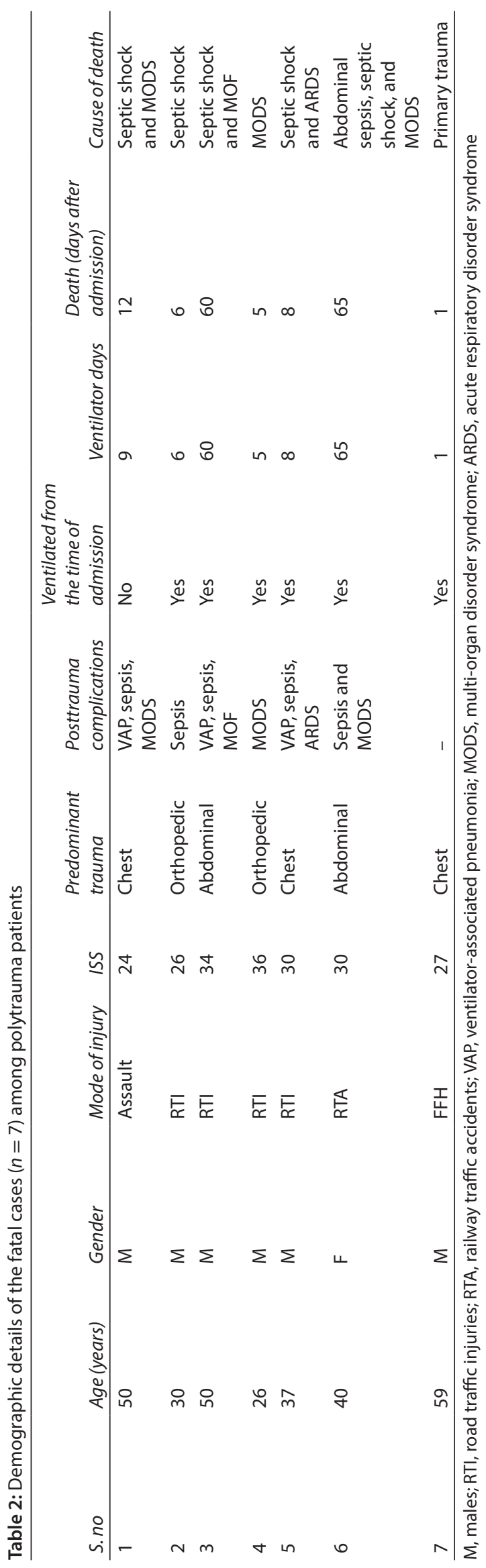




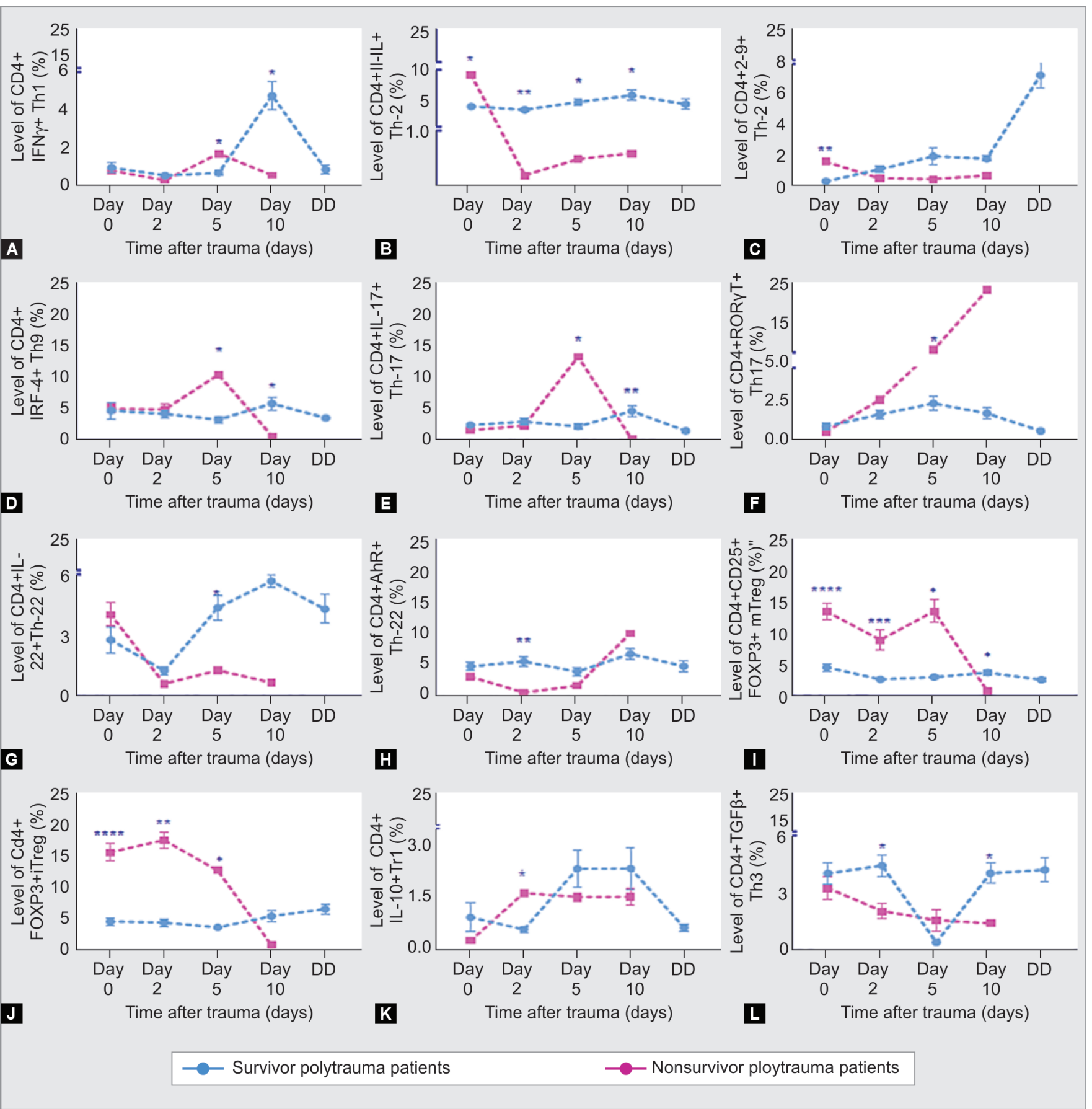

Figs $1 \mathrm{~A}$ to L: Comparison of levels of Thelper cells in peripheral blood, based on the clinical outcome of polytrauma patients

found to be higher in nonsurvivors than in survivors from day 0 ( $p$ $<0.0001$ ) till day 5 ( $p=0.0131)$ (Fig. $1 \mathrm{~J})$. Tr1 cells were observed to be higher in survivors, except for day 2 , when they were higher in nonsurvivors ( $p=0.0167$ ) (Fig. 1K). Th-3 cells were also found to be higher in survivors and this elevation was found to be statistically significant on day $2(p=0.0424)$ and day 10 ( $p=0.0167)$ (Fig. $1 \mathrm{~L})$.

\section{Dynamics of Serum Cytokines Based on Clinical Outcome of Polytrauma Patients}

As shown in Figure 2, IFN- $\gamma$ was found to be lower in nonsurvivors. The depression was statistically significant on day $0(p=0.0332)$ and day 2 ( $p=0.00009$ ) (Fig. 2A). TNF-a was observed to be lower in nonsurvivors and was found to be statistically significant on day $0(p=0.0052)$, day $2(p=0.0017)$, and day 5 ( $p=0.0105)$ (Fig. $2 \mathrm{~B})$. IL-2 was found to be lower in nonsurvivors. The depression was statistically significant on day $2(p=0.0437)$ and day $10(p=$ 0.0167) (Fig. 2C). IL-4 was found to be lower in nonsurvivors. The depression was statistically significant on day $2(p=0.0487)$ and day $10(p=0.0351)$ (Fig. 2D). IL-5 was found to be lower in nonsurvivors. The depression was statistically significant on day 10 ( $p=0.0281)$ (Fig. 2E). IL-6 was higher in nonsurvivors and the difference was found to be statistically significant on day $0(p<0.0001)$, day 2 ( $p=$ 

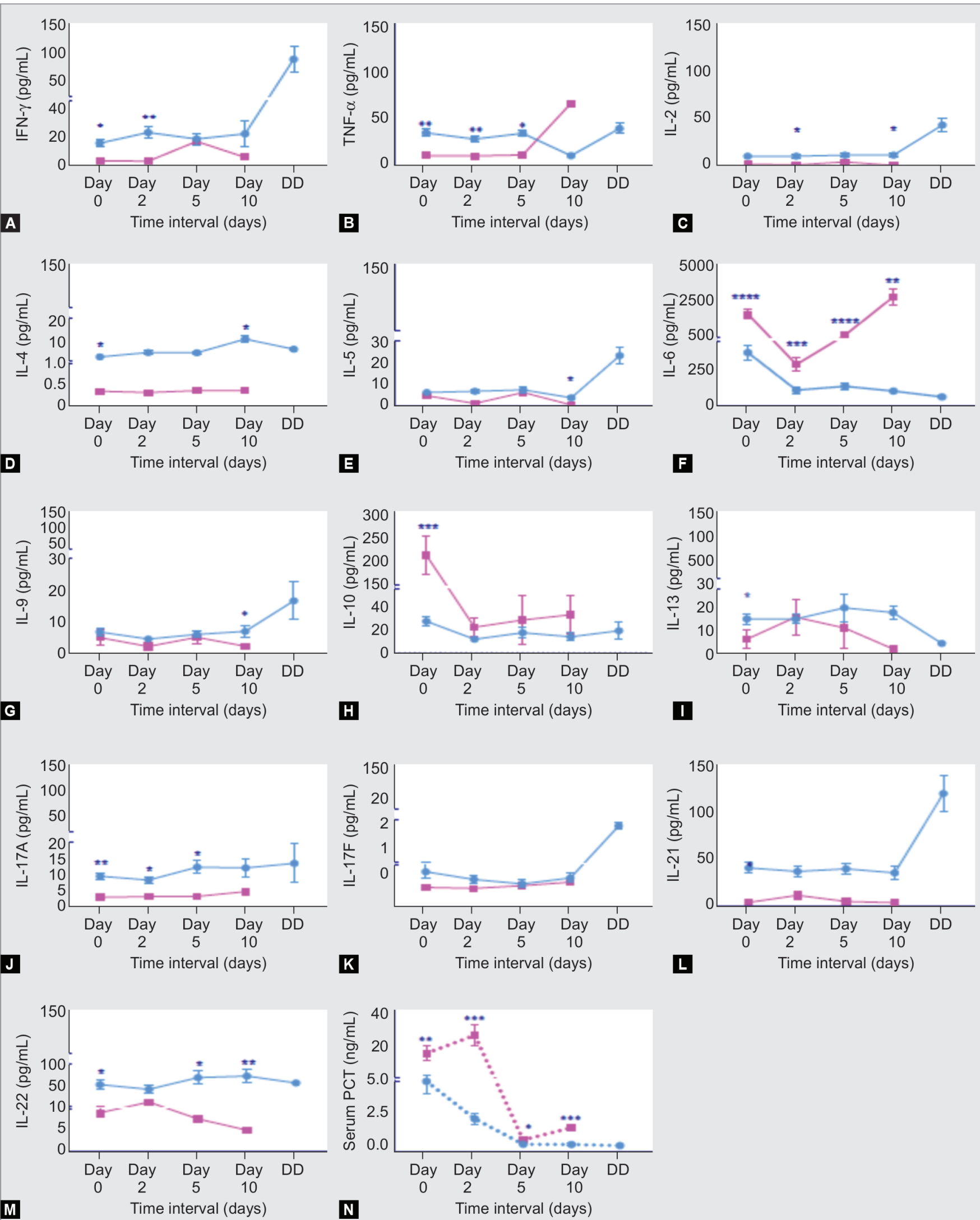

- Survivor polytrauma patients

- Nonsurvivor ploytrauma patients

Figs $2 \mathrm{~A}$ to N: Comparison of levels of serum cytokines and PCT based on the clinical outcome of polytrauma patients 
$0.0009)$, day $5(p<0.0001)$, and day $10(p=0.0018)$ (Fig. 2F). IL-9 was found to be lower in nonsurvivors. The depression was statistically significant on day 10 ( $p=0.0149$ ) (Fig. 2G). IL-10 was statistically significantly higher in nonsurvivors on day 0 ( $p=0.0009$ ) (Fig. $2 \mathrm{H}$ ). IL-13 was found to be lower in nonsurvivors. The depression was statistically significant on day $0(p=0.0308)$ (Fig. 2I). IL-17A was found to be lower in nonsurvivors. The depression was statistically significant on day $0(p=0.0078)$, day $2(p=0.0410)$, and day 5 ( $p=$ 0.0342) (Fig. 2J). IL-17F was found to be lower in nonsurvivors. The depression, however, was not found to be statistically significant (Fig. 2K). IL-21 was found to be lower in nonsurvivors. The depression was statistically significant on day 0 ( $p=0.0226$ ) (Fig. 2L). IL-22 was observed to be lower in nonsurvivors. The depression was statistically significant on day $0(p=0.0128)$, day $5(p=0.0188)$, and day 10 ( $p=0.0096)$ (Fig. 2M).

\section{Serum PCT Levels Based on Clinical Outcome in Polytrauma Patients}

Elevated levels of serum PCT were found in the polytrauma patients who had a fatal outcome. This elevation was found to be statically significant on day $0(p=0.0060)$, day $2(p=0.0002)$, day $5(p=$ $0.0437)$, and day $10(p=0.0081)$. A shown in Figure $2 \mathrm{~N}$, serum PCT was statistically significantly higher in nonsurvivors in from the time of injury till their clinical outcome, strongly suggesting that serum PCT may be used as a poor prognostic marker.

\section{Discussion}

The complex interplay between inflammation and physiology following initial traumatic insult begins with the instant activation of innate immunity due to disruption of macrobarriers like the skin, along with microbarriers like cell membranes, leading to the release of multiple danger molecules. ${ }^{17,36}$ The innate immune response after life-threatening polytrauma results in a multifaceted systemic disease with a complex, heterogeneous, and mainly tissue-specific response. $^{37}$

A successful immune response to a pathogen depends on the finely orchestrated interactions among diverse cell types. These cells include the innate immune cells, i.e., NK cells, mast cells, eosinophils, basophils, as well as the phagocytic cells (macrophages, neutrophils, and dendritic cells) and adaptive immune cells, i.e., the T and B lymphocytes (involved in mounting the first line of defense against pathogens), and antigen-presenting cells (involved in communicating the infection to lymphoid cells, which coordinate the adaptive response and generate the memory cells that prevent future infections). ${ }^{14}$
Table 3 summarizes the statistically significant elevation and depression of Thelper subsets in different posttrauma phases. We saw a higher percentage of Th-1 (except day 5), Th-2 (except day 0 ), IL-9+Th-9 (except day 0), IL17+Th-17 (except day 5), and IL-22+Th-22 and AhR+Th-22 cells in the patients who were discharged, while, a relatively higher IRF4+Th-9, RORYT+Th-17 (except day 0 ) cells were found in nonsurvivors, suggesting that the higher IFN- $\gamma$, IL-4+, IL-9+, IL17+, and IL-22+ cells played a protective role in the survival of polytrauma patients. Among the regulatory T helper cells, lower nTreg and iTreg, while higher Tr1 and Th-3 cell percentages in the peripheral blood led to a favorable outcome. These markers could thus be used as early predictors of adverse outcomes and can be a target for future therapeutics.

Cuiyan et al. have demonstrated a close relationship between Th-2 and Th-9 cells and reported the existence of a "two-way traffic" between these two cell types, and a moderate level of plasticity when polarized toward Th-1 or Th-17 lineages. ${ }^{38}$ Nagalakshmi et al. showed that IL-22 is involved in the functional activation and maintenance of structural integrity of intestinal epithelial lining by inducing expression of genes that regulate processes like proliferation, wound healing, and apoptosis. ${ }^{39,40}$ These studies support the simultaneously higher levels of IL-4+, IL-9+, IL17+, and $\mathrm{IL}-22+$ cells in our polytrauma patients who survived.

It was also observed that the transcriptionally active cells may not always be functionally active, since there was a difference between the cell types expressing the signature cytokines and those expressing the master transcription factors.

Although most of the trauma victims lack any underlying ailments or comorbidities, trauma elicits a complex, dynamic, multidimensional inflammatory response that is intertwined with complications in organ systems not necessarily affected by the primary trauma; posttrauma complications, like bloodstream infection, VAP, ARDS, SIRS, sepsis, and MODS, account for a large number of fatalities. ${ }^{41-43}$

It interested us to find that the levels of serum TNF- $a$, IFN- $\gamma$, IL-2, IL-4, IL-5, IL-9, IL-13, IL-17A, IL-17F, IL-21, and IL-22 were higher in the survivor cohort, suggesting that these cytokines may be playing protective roles in the immunopathogenesis of polytrauma patients. In concordance with our findings are the findings reported by Abboud et al. that IL-22 was the only mediator that was statistically significantly raised in the survivor cohort, while IL-17 may be involved in organ damage, survival, as well as mortality following blunt trauma, suggesting that Th-17 cells may have cellbased inflammation switch from self-resolving to self-sustaining. They also showed that in survivors, there were strongly linked

Table 3: Role of T helper lymphocytes in posttrauma immunopathogenesis and outcome of polytrauma patients

\begin{tabular}{|c|c|c|c|c|c|c|c|}
\hline & \multirow[b]{2}{*}{ Response } & \multicolumn{2}{|c|}{ Early phase (day 2) } & \multicolumn{2}{|c|}{ Mid phase (day 5) } & \multicolumn{2}{|c|}{ Late phase (day 10) } \\
\hline & & Thelper cells & Cytokines & Thelper cells & Cytokines & Thelper cells & Cytokines \\
\hline \multirow[t]{9}{*}{ Nonsurvivors } & High & nTreg & IL-6 & Th-1 & IL-6 & RORYT+Th-17 & IL-6 \\
\hline & & iTreg & & IRF4+Th-9 & & & \\
\hline & & $\operatorname{Tr} 1$ & & $\begin{array}{l}\text { IL17+ Th-17 RORYT+ Th- } \\
17 \text { nTreg }\end{array}$ & & & \\
\hline & & & & iTreg & & & \\
\hline & Low & Th-2 & $\mathrm{IFN} \gamma$ & Th-2 & TNF- $a$ & Th-1 Th-2 & IL-2 \\
\hline & & Th-3 & TNF-alL-2 & IL-22+Th-22 & IL-17A & IRF4+Th-9 & IL-4 \\
\hline & & & IL-4 & AhR Th-22 & IL-22 & IL17+ Th-17 & IL-5 \\
\hline & & & IL-17A & & & nTreg & IL-9 \\
\hline & & & & & & Th-3 & IL-22 \\
\hline
\end{tabular}


networks of interaction between IL-5 and IL-13; IL-17A, IL 4, and sIL-2Ra; as well as between IL-22 and IL-23. ${ }^{44}$

Another interesting finding was elevated levels of IL- 6 and IL-10 in the serum of polytrauma patients who developed complications and in those who had a fatal outcome. Both Th- 9 and Tregs secrete IL-10, and Th-1, Th-2, Th-17, and Th-22 cells have been reported to secrete both IL- 6 and IL-10. Stensballe et al. have previously reported the correlation of IL- 6 and IL-10 response in trauma with injury severity and mortality, within the first 24 hours. ${ }^{45}$ Various other studies have also shown the role of IL- 6 in the early diagnosis of posttrauma complications. ${ }^{7,8,35,46}$

Our data are highly suggestive of the prognostic utility of IL-6 and IL-10 in the immunopathogenesis of polytrauma patients since we analyzed the results based on various parameters and until their day of discharge from the hospital.

\section{Strengths of the Study}

We studied the T helper lymphocytic cytokine and transcription factor activity, using the intracellular staining technique and flowcytometry. T helper lymphocytes are the main effector cells in the immediate immunological response. Thus, studying its activity using a single cell-based technique adds to the scientific quality and validity of data. We followed up the patients on days $0,2,5$, 10 , and the day of discharge. Most immunologically driven/late complications of trauma occur between days 3 and 10 of trauma. The initial days are essential to ascertain the immediate immunological reaction to trauma. Thus, the presented work led us to important findings in the field of trauma immunology.

\section{Limitations of the Study}

There were a few limitations in our study; we included a large heterogeneity of patients (differing in injury severity and type of trauma). A large and hemogeneous cohort of cases may have been better to postulate a working model of prognostication by cytokines and biomarkers.

Apart from the primary trauma, secondary sepsis (as 6/7 patients in nonsurvivors died because of sepsis) may also have been responsible for an immune response, especially in the delayed phase.

Finally, a larger study incorporating analysis of other immune cells like neutrophils, B cells, $\gamma \delta T$ cells, monocytes, etc., apart from many other biomarkers could give a more holistic view of the posttrauma immune pathogenesis, which would, however, be a very expensive study.

\section{Conclusion}

In the present study, different Th-subsets were observed to be playing pathogenic and protective roles in different phases of trauma and could be used for early prognostication. These markers could lead us to develop targeted immunomodulation therapies for noninvasive management of critically injured trauma patients.

Along with growing and improving trauma networks, priorities for future investigations comprise of using a systems biology viewpoint to track the changes and the underlying molecular machinery and their biological relevance to identify the most propitious therapeutic targets, to then design appropriate clinical trials, and judiciously selecting results from trials in trauma care to support treatment of trauma patients.

\section{References}

1. Singh D, Singh SP, Kumaran M, Goel S. Epidemiology of road traffic accident deaths in children in Chandigarh zone of North West India. Egypt J Forensic Sci 2016;6(3):255-260. DOI: 10.1016/j.ejfs.2015.01.008.

2. WHO. Global Health Estimates 2016: Deaths by Cause, Age, Sex, by Country and by Region, 2000-2016. Geneva, World Health Organization: WHO Press; 2018.

3. WHO, World Health Organization. Global status report on road safety 2015: Road safety targets and the Sustainable Development Goals WHO Press 2015.

4. WHO, World Health Organization. Global status report on road safety 2013: supporting decades of action WHO Press 2013.

5. Haagsma JA, Graetz N, Bolliger I, Naghavi M, Higashi H, Mullany $\mathrm{EC}$, et al. The global burden of injury: incidence, mortality, disability-adjusted life years and time trends from the global burden of disease study 2013. Inj Prev 2016;22(1):3-18. DOI: 10.1136/ injuryprev-2015-041616.

6. Rastogi D, Meena S, Sharma V, Singh GK. Epidemiology of patients admitted to a major trauma centre in northern India. Chinese $J$ Traumatol 2014;17(2):103-107.

7. Kimura F, Shimizu H, Yoshidome H, Ohtsuka M, Miyazaki M. Immunosuppression following surgical and traumatic injury. Surg Today 2010;40(9):793-808. DOI: 10.1007/s00595-010-4323-z.

8. Osuka A, Ogura H, Ueyama M, Shimazu T, Lederer JA. Immune response to traumatic injury: harmony and discordance of immune system homeostasis. Acute Med Surg 2014;1(2):63-69. DOI: 10.1002/ ams2.17.

9. Lederer JA, Rodrick ML, Mannick JA. The effects of injury on the adaptive immune response. Shock 1999;11(3):153-159. DOI: 10.1097/00024382-199903000-00001.

10. Lord JM, Midwinter MJ, Chen Y-F, Belli A, Brohi K, Kovacs EJ, et al. The systemic immune response to trauma: an overview of pathophysiology and treatment. 2014;384(9952):1455-1465.

11. Sauaia A, Moore FA, Moore EE. Postinjury inflammation and organ dysfunction. Crit Care Clin 2017;33(1):167-191. DOI: 10.1016/j. ccc.2016.08.006.

12. Mira JC, Cuschieri J, Ozrazgat-Baslanti T, Wang Z, Ghita GL, Loftus $\mathrm{TJ}$, et al. The epidemiology of chronic critical illness after severe traumatic injury at two level-one trauma centers. Crit Care Med 2017;45(12):1989-1996. DOI: 10.1097/CCM.0000000000002697.

13. Callcut RA, Wakam G, Conroy AS, Kornblith LZ, Howard BM, Campion EM, et al. Discovering the truth about life after discharge: long-term trauma related mortality. J Trauma Acute Care Surg 2016;80(2):210217. DOI: $10.1097 /$ TA.0000000000000930.

14. Punt J, Owen JA, Stranford SA, Jones PP, Kuby J. Kuby Immunology 2019.

15. Lanier LL. Shades of grey - the blurring view of innate and adaptive immunity. Nat Rev Immunol 2013;13(2):73-74. DOI: 10.1038/nri3389.

16. Vivier E, Raulet DH, Moretta A, Caligiuri MA, Zitvogel L, Lanier LL, et al. Innate or adaptive immunity? The example of natural killer cells. Science 2011;331(6013):44-49. DOI: 10.1126/science.1198687.

17. Huber-Lang $M$, Lambris JD, Ward PA. Innate immune responses to trauma. Nat Immunol 2018;19(4):327-341. DOI: 10.1038/s41590-0180064-8.

18. Raphael I, Nalawade S, Eagar TN, Forsthuber TG. Cytokine T cell subsets and their signature cytokines in autoimmune and inflammatory diseases. Cytokine 2015;74(1):5-17. DOI: 10.1016/j. cyto.2014.09.011.

19. Jia LWC. Differentiation, regulation and function of Th9 cells. Adv Exp Med Biol 2014;841:181-207.

20. Kaplan M. Th9 cells: differentiation and disease. Immunol Rev 2013;252(1):104-115. DOI: 10.1111/imr.12028.

21. Tan C, Gery I. The unique features of Th9 cells and their products. Crit Rev Immunol 2012;32(1):1-10. DOI: 10.1615/CritRevImmunol.v32.i1.10.

22. Moseley TA, Haudenschild DR, Rose L, Reddi AH. Interleukin-17 family and IL-17 receptors. Cytokine Growth Fact Rev 2003;14(2):155-174. DOI: 10.1016/S1359-6101(03)00002-9. 
23. Kolls JK, Lindén A. Interleukin-17 family members and inflammation. Immunity 2004;21(4):467-476. DOI: 10.1016/j.immuni.2004.08.018.

24. McKenzie BS, Kastelein RA, Cua DJ. Understanding the IL-23-IL-17 immune pathway. Trends Immunol 2006;27(1):17-23. DOI: 10.1016/j. it.2005.10.003.

25. Trifari S, Spits H. IL-22-producing CD4+ T cells: middle-men between the immune system and its environment. Eur J Immunol 2010;40(9):2369-2371. DOI: 10.1002/eji.201040848.

26. Trifari S, Kaplan CD, Tran EH, Crellin NK, Spits H. Identification of a human helper $\mathrm{T}$ cell population that has abundant production of interleukin 22 and is distinct from Th-17, Th 1 and Th 2 cells. Nat Publ Gr 2009;10(8):864-871.

27. Wolff MJ, Leung JM, Davenport M, Poles MA, Cho I, Loke P. Th 17, Th 22 and Treg cells are enriched in the healthy human cecum. PLoS ONE 2012;7(7):e41373. DOI: 10.1371/journal.pone.0041373.

28. Eyerich S, Eyerich K, Pennino D, Carbone T. Th-22 cells represent a distinct human $\mathrm{T}$ cell subset involved in epidermal immunity and remodeling. J Clin Invest 2009;119:3573-3585.

29. Sugita S, Kawazoe $Y$, Imai A, Kawaguchi T, Horie S, Keino H, et al. Role of IL-22- and TNF-producing Th22 cells in uveitis patients with Behcet's disease. J Immunol 2013;190(11):5799-5808. DOI: 10.4049/ jimmunol.1202677.

30. Kumar P, Rajasekaran K, Palmer JM, Thakar MS. IL-22: an evolutionary missing-link authenticating the role of the immune system in tissue regeneration. J Cancer 2013;;4(1):57. DOI: 10.7150/jca.5048.

31. Duhen T, Geiger R, Jarrossay D, Lanzavecchia A, Sallusto F. Production of interleukin 22 but not interleukin 17 by a subset of human skinhoming memory T cells. Nat Immunol 2009;10(8):857-863. DOI: 10.1038/ni.1767.

32. Wan S, Xia C, Morel L. The B, sle S, tc B. IL-6 produced by dendritic cells from lupus-prone mice inhibits CD4+CD25+ T cell regulatory functions. J Immunol 2007;178(1):271-279. DOI: 10.4049/ jimmunol.178.1.271.

33. Sakaguchi S. Naturally arising CD4+ regulatory T cells for immunologic self -tolerance and negative control of immune responses. Annu Rev Immunol 2004;22(1):531-562. DOI: 10.1146/ annurev.immunol.21.120601.141122.

34. Horwitz DA, Gray JD, Zheng SG. The potential of human regulatory T cells generated ex vivo as a treatment for lupus and other chronic inflammatory diseases. Arthritis Res Ther 2002;4(4):241-246. DOI: 10.1186/ar414.

35. Dai H, Sun T, Liu Z, Zhang J, Zhou M. The imbalance between regulatory and IL-17-secreting CD4 + T cells in multiple-trauma rat. Injury 2013;44(11):1521-1527. DOI: 10.1016/j.injury.2013.03.015.

36. Namas RA, Mi Q, Namas $R$, Almahmoud K, Zaaqoq AM, Abdul-Malak $\mathrm{O}$, et al. Insights into the role of chemokines, damage-associated molecular patterns, and lymphocyte-derived mediators from computational models of trauma-induced inflammation. Antioxid Redox Signal 2015;23(17):1370-1387. DOI: 10.1089/ars.2015.6398.

37. Gabbe BJ, Simpson PM, Cameron PA, Ponsford J, Lyons RA, Collie $A$, et al. Long-term health status and trajectories of seriously injured patients: a population-based longitudinal study. PLoS Med 2017;14(7):1-18. DOI: 10.1371/journal.pmed.1002322.

38. Tan C, Aziz MK, Lovaas JD, Vistica BP, Shi G, Wawrousek EF, et al. Antigen-specific Th9 cells exhibit uniqueness in their kinetics of cytokine production and short retention at the inflammatory site. J Immunol 2010;185(11):6795-6801. DOI: 10.4049/jimmunol.1001676.

39. Nagalakshmi ML, Rascle A, Zurawski S, Menon S, de Waal, Malefyt R. Interleukin-22 activates STAT3 and induces IL-10 by colon epithelial cells. Int Immunopharmacol 2004;4(5):679-691. DOI: 10.1016/j. intimp.2004.01.008.

40. Pickert G, Neufert C, Leppkes M, Zheng Y, Wittkopf N, Warntjen M, et al. STAT3 links IL-22 signaling in intestinal epithelial cells to mucosal wound healing. J Exp Med 2009;206(7):1465-1472. DOI: 10.1084/ jem.20082683.

41. Miller AC, Rashid RM, Elamin. EM. The "T" in trauma: the helper T-cell response and the role of immunomodulation in trauma and burn patients. J Trauma, Inj Infect Crit Care 2007;63(6):1406-1417. DOI: 10.1097/TA.0b013e31815b839e.

42. Mommsen P, Frink M, Pape HC, van Griensven M, Probst C, Gaulke R, et al. Elevated systemic IL-18 and neopterin levels are associated with posttraumatic complications among patients with multiple injuries: a prospective cohort study. Injury 2009;40(5):528-534. DOI: 10.1016/j. injury.2008.08.007.

43. Khurana $S$, Mathur $P$, Kumar $S$, Soni K, Aggrawal R, Batra $P$, et al. Incidence of ventilator-associated pneumonia and impact of multidrug-resistant infections on patient's outcome: experience at an apex trauma centre in North India. Indian J Med Microbiol 2017;35(4):504-510. DOI: 10.4103/ijmm.IJMM_16_186.

44. Abboud A, Namas RA, Ramadan M, Mi Q, Almahmoud K, AbdulMalak $\mathrm{O}$, et al. Computational analysis supports an early, type 17 cell-associated divergence of blunt trauma survival and mortality. Crit Care Med 2016;44(11):e1074-e1081. DOI: 10.1097/ CCM.0000000000001951.

45. Stensballe J, Christiansen M, Tønnesen E, Espersen K, Lippert FK, Rasmussen LS. The early IL- 6 and IL-10 response in trauma is correlated with injury severity and mortality. Acta Anaesthesiol Scand 2009;53(4):515-521. DOI: 10.1111/j.1399-6576.2008.01801.x.

46. Billeter A, Turina M, Seifert B, Mica L, Stocker R, Keel M. Early serum procalcitonin, interleukin-6, and 24-hour lactate clearance: useful indicators of septic infections in severely traumatized patients. World J Surg 2009;33(3):558-566. DOI: 10.1007/s00268-008-9896-y. 